\title{
Gerenciamento do pessoal de enfermagem com estabilidade no emprego: percepção de enfermeiros
}

\author{
Management of nursing personnel with job security: perceptions of nurses
}

Gerencia del personal de enfermería con estabilidad en el empleo: percepciones de los enfermeros

\section{Amanda Troca Guimarães', Helena Heidtmann Vaghetti", Wilson Danilo Lunardi Filho", Giovana Calcagno Gomes ${ }^{1}$}

' Universidade Federal do Rio Grande, Escola de Enfermagem. Rio Grande-RS, Brasil.

"Universidade Federal do Rio Grande, Escola de Enfermagem, Grupo de Estudos e Pesquisas sobre

Organização do Trabalho da Enfermagem e Saúde. Rio Grande-RS, Brasil.

Submissão: 24-01-2011 Aprovação: 09-12-2011

\section{RESUMO}

Objetivou-se identificar a percepção de enfermeiros de um hospital universitário sobre o gerenciamento do pessoal de enfermagem com estabilidade no emprego. Pesquisa qualitativa desenvolvida em 2010 com dezesseis enfermeiros. Dados coletados por entrevistas semi-estruturadas e analisados pela Análise Temática geraram duas categorias empíricas: $A$ segurança no trabalho versus a impunidade proporcionada pela estabilidade no emprego; e $O$ (des)comprometimento no trabalho da enfermagem e a estabilidade no emprego. Verificou-se que estabilidade no emprego oferece segurança no trabalho; essa segurança produz impunidade, e os enfermeiros resistem em conduzir processos administrativos. Conclui-se que a segurança favorece a quebra de hierarquias, a impunidade gera a banalização das transgressões, pela falta de medidas administrativas ágeis para resolução de problemas; e a estabilidade no emprego não garante a qualidade da assistência.

Descritores: Enfermagem; Hospitais públicos; Recursos humanos de enfermagem no hospital; Administração de recursos humanos em hospitais.

\begin{abstract}
This study aimed to identify a university hospital nurses' perception on the management of nursing personnel with job security, using data collected from a qualitative research developed with sixteen nurses, in 2010. The data, collected through semi-structured interviews, and analyzed by Thematic Analysis, produced two empirical categories: Security at work versus the impunity afforded by tenure; Job stability and (un)involvement in nursing work. It has been verified that job stability provides security of employment; security spawns impunity, and nurses are reluctant to conduct administrative proceedings. The conclusion are that the security of employment caused by stability can favour the break of hierarchies; impunity leads to the vulgarisation of transgressions by the lack of effective administrative measures toward the solution of problems; and job stability does not ensure the quality of assistance.
\end{abstract}

Key words: Nursing; Hospitals, Public; Nursing staff, hospital; Personnel administration, hospital.

\section{RESUMEN}

El objetivo fue identificar la percepción de los enfermeros de un hospital universitario frente la gerencia del personal de enfermería con estabilidad laboral. Encuesta cualitativa desarrollada en 2010 con dieciséis enfermeros. Los datos, recogidos por entrevistas semi-estructuradas y analizados por el Análisis Temática, generarán dos categorías: La seguridad en el trabajo versus la impunidad otorgada por la estabilidad laboral; y La participación o no en el trabajo de enfermería y la estabilidad laboral. Se verificó que estabilidad en el empleo ofrece seguridad en el trabajo; que la seguridad genera impunidad, y que los enfermeros resisten en tramitar procesos administrativos. Se concluye que: seguridad puede beneficiar la ruptura de las jerarquías; la impunidad en los servicios públicos genera una trivialización de transgresiones por la falta de medidas administrativas rápidas para la resolución de los problemas; la estabilidad en el empleo no garantiza calidad en la asistencia

Descriptores: Enfermería; Hospitales Públicos; Personal de Enfermería en Hospital; Administración de Personal en Hospitales. 


\section{INTRODUÇÃO}

O artigo 20 da lei $n^{\circ} 8.112$, de 1990 garante estabilidade no emprego aos servidores públicos brasileiros após dois anos de efetivo exercício do cargo ${ }^{(1)}$. Em 1998, por meio da Emenda Constitucional 19, o tempo para aquisição da estabilidade no emprego passou para três anos. Nesse período, conhecido como estágio probatório, são avaliados critérios como assiduidade, disciplina, produtividade, responsabilidade e capacidade de iniciativa, os quais fazem parte das atribuições do cargo. Expirado esse prazo, de acordo com o artigo 22 da referida Emenda, o servidor público só perderá o cargo em virtude de condenação judicial ou administrativa( ${ }^{(2)}$. Expresso de outro modo, passado o período probatório, o trabalhador adquire estabilidade no emprego.

A cada dia aumenta o número de pessoas que se preparam para ingressar, por meio de concursos, no serviço público no Brasil. A concorrência geralmente é grande e a conquista de uma vaga requer dedicação aos estudos e, não raro, a realização de cursos preparatórios com o objetivo primeiro de aprovação e classificação para ocupar um cargo e o alcance posterior da estabilidade no emprego.

Esse aumento revela a luta pela estabilidade que, como direito, deve estar acessível a todos os cidadãos. Acima disto, revela que a estabilidade é percebida como uma vantagem do ponto de vista social e econômico, pois oferece tranqüilidade à vida dos indivíduos ${ }^{(3)}$, uma vez que significa a possibilidade de um salário permanente( ${ }^{(4)}$.

Assim, na atualidade, é possível entender um dos principais motivos pelos quais as pessoas buscam, cada vez mais, conquistar uma vaga no serviço público: a garantia de benefícios vitalícios ${ }^{(5)}$. Este fato é reiterado por estudo intitulado "Cultura organizacional em organizações públicas no Brasil", no qual, para a maioria dos entrevistados, "a estabilidade consistiu na principal razão para a entrada no serviço público"(6).

$\mathrm{Na}$ particularidade da Enfermagem, esta realidade é comum entre os recém-egressos dos cursos técnicos e de graduação, que aspiram por vagas em organizações públicas, pois a perspectiva de estabilidade no emprego está à frente das pretensões salariais ${ }^{(7)}$.

Mesmo com a dificuldade de ingresso, o pessoal de Enfermagem já é a maioria nos serviços públicos de saúde, com 76.399 enfermeiros, 76.747 técnicos de enfermagem e 146.034 auxiliares, totalizando $29 \%$ do quadro de servidores públicos da área da saúde ${ }^{(8)}$. Estes dados deveriam suscitar muitos estudos acerca da estabilidade no emprego, mas, em buscas bibliográficas com os descritores "enfermagem" e "estabilidade" nos sistemas Medline, Lilacs Express, SciELO e Portal de Periódicos da Capes, entre outros, verifica-se que esta não é uma prática usual.

Dentre as investigações encontradas está a intitulada "Motivação da equipe de enfermagem em uma unidade de terapia intensiva", que mostrou a existência de dois lados da estabilidade no emprego: o positivo e o negativo. Como aspectos positivos foram citados o estímulo e o desafio no trabalho, a realização profissional, o reconhecimento pelo trabalho realizado, a exigência de responsabilidade no trabalho, a chance de progresso e crescimento profissional. Já os aspectos negativos incluíram a falta de interesse do trabalhador, os atrasos, os altos índices de absenteísmo e a apresentação de atestados médicos, além do não cumprimento de tarefas programadas e designadas pelo enfermeiro da unidade ou setor. Atitudes como essas interferem não só no trabalho da equipe, mas também na saúde dos pacientes assistidos por esses profissionais ${ }^{(9)}$.

Outros autores também referem que a estabilidade no emprego nem sempre origina e garante um bom desempenho no trabalho. Seus estudos identificaram diversos pontos negativos, como desmotivação e ineficiência, transgressão de normas e falta de comprometimento, além de desperdício e descuido com aquilo que é público, presentes em organizações de saúde com trabalhadores estabilizados no emprego ${ }^{(6,10-11)}$.

Como enfermeiros, inúmeras vezes presenciamos na realidade hospitalar pública situações como as expostas anteriormente. Essas experiências levaram-nos a questionar como outros enfermeiros vêm gerenciando o pessoal de Enfermagem com estabilidade no emprego e o quanto isto interfere seu trabalho, facilitando-o ou dificultando-o, uma vez que, conforme o Art. 11 da Lei ${ }^{\circ}$ 7.498/86, é privativo do enfermeiro:

a) direção do órgão de enfermagem integrante da estrutura básica da instituição de saúde, pública e privada, e chefia de serviço e de unidade de enfermagem;

b) organização e direção dos serviços de enfermagem e de suas atividades técnicas e auxiliares nas empresas prestadoras desses serviços ${ }^{(12)}$.

Diante desta problemática, este estudo teve como objetivo identificar a percepção de enfermeiros de um hospital universitário sobre o gerenciamento do pessoal de Enfermagem com estabilidade no emprego.

O alcance do objetivo proposto poderá auxiliar no gerenciamento do pessoal de Enfermagem, oportunizando aos enfermeiros reflexões acerca da estabilidade no emprego, os direitos e os deveres que dela decorrem. Esta investigação poderá ainda suscitar futuras estratégias de gerenciamento do pessoal de Enfermagem para fazer face às dificultadas apontadas.

\section{METODOLOGIA}

Trata-se de uma pesquisa qualitativa, de caráter descritivo-exploratório, desenvolvida em um hospital universitário da região sul do Brasil, no período compreendido entre os meses de janeiro a junho de 2010. Participaram do estudo 16 enfermeiros de quatro unidades de internação ( 3 da Clínica Médica, 4 da Clínica Cirúrgica, 5 da Maternidade/Convênios e 4 da Pediatria) dos turnos da manhã, tarde, noite. Todos assinaram o termo de consentimento livre e esclarecido, além de permitirem a gravação de suas entrevistas e divulgação dos resultados. Os participantes foram identificados por ENF e por números, conforme a ordem na qual foram entrevistados, a fim de garantir o sigilo e o anonimato.

A coleta de dados foi realizada por meio de entrevistas individuais semiestruturadas, que foram agendadas previamente, 
gravadas, transcritas e posteriormente validadas pelos enfermeiros entrevistados. Para a análise dos dados utilizou-se a Análise Temática, baseada em Bardin, que consiste em três passos: pré-análise; exploração do material empírico e tratamento, inferências e interpretação dos $\operatorname{dados}^{(13)}$.

O estudo foi aprovado pelo Comitê de Ética em pesquisa na Área de Saúde onde foi realizada a pesquisa (Parecer $N^{\circ}$ 12/2010 - CEPAS).

\section{RESULTADOS E DISCUSSÃO}

Núcleos temáticos como segurança no trabalho, impunidade, comprometimento, qualidade da assistência, entre outros, foram agrupados em categorias empíricas, que compuseram a percepção dos enfermeiros sobre o gerenciamento do pessoal de Enfermagem com estabilidade no emprego, apresentada a seguir.

\section{A segurança no trabalho versus a impunidade proporcio- nada pela estabilidade no emprego}

A segurança no trabalho foi considerada um ponto positivo para os trabalhadores entrevistados. As manifestações a esse respeito e o entendimento de que a estabilidade no emprego deveria ser estendida como direito a todos os trabalhadores são evidenciadas nos excertos a seguir.

A estabilidade é ótima. É ótima pela questão da remuneração. É ótima pela questão da estabilidade mesmo. Então, claro que para os trabalhadores isso é ótimo. Quisera todos os trabalhadores tivessem estabilidade. (ENF 8)

Eu acho que a estabilidade é uma coisa muito boa, pois valoriza o trabalho... Eu acho que é ótimo ter estabilidade. Eu acho que estabilidade devia ser pra todos os trabalhadores. (ENF 2)

Pode-se afirmar que o empregado estável vive melhor, tem dignidade no meio social e pode dar segurança a sua família, pela garantia de manutenção de seu emprego ${ }^{(14)}$. A estabilidade no emprego proporciona segurança no trabalho, perspectiva de aposentadoria e um futuro tranqüilo, sendo também sinônimo de proteção contra a dispensa sem uma causa justa ${ }^{(7,11,15)}$.

A estabilidade é tão importante para os trabalhadores de Enfermagem que o estudo "Estresse na enfermagem: mensuração das situações geradoras em um hospital geral"(16), realizado em um hospital onde os trabalhadores não possuíam estabilidade, identificou que sua ausência ocasiona grande estresse entre os enfermeiros.

A segurança no trabalho oferecida pela estabilidade no emprego também envolve a possibilidade do trabalhador de Enfermagem ausentar-se do trabalho para cuidar um de familiar enfermo sem ser demitido por faltas. Isto é assegurado pelo Regime Jurídico Único que, desde 1997, por meio da Lei 9.527, em seu Art. 83 $3^{(17)}$, permite aos trabalhadores estáveis gozar de licença remunerada de até sessenta dias, consecutivos ou não, por motivo de doença de cônjuge ou companheiro, pais, filhos, padrasto ou madrasta, enteado ou dependente que viva às suas expensas e conste de seu assentamento funcional, mediante comprovação por junta médica oficial.

Outro aspecto da segurança gerada pela estabilidade no emprego diz respeito à horizontalidade das relações entre chefia e trabalhadores. Segundo os entrevistados, no hospital onde foi realizada a pesquisa, os trabalhadores não se sentem inferiorizados perante seus superiores. Ao contrário, a estabilidade fomenta uma relação sem temores ou diferenças. Nessa realidade, não há abuso de poder, mas trocas de idéias entre os integrantes da equipe de Enfermagem, em que os superiores não são vistos como "chefes", mas como colegas de trabalho que possuem os mesmos direitos, privilégios, deveres e obrigações.

Porque, assim, eu sou superior, mas sou tua colega [...] (ENF 12)

É melhor tu saberes que tu tens a chance de alguém te advertir e fazer com que tu melhores do que simplesmente "tu não serves, vai pra rua", sem te dar chance nenhuma. (ENF 6)

Sob esta ótica, a segurança no trabalho, no entender dos entrevistados, facilita o gerenciamento do pessoal de Enfermagem, pois a satisfação dos trabalhadores advinda do diálogo e da possibilidade de desenvolvimento do trabalho sem pressão e sem perseguição por parte da chefia colabora para o bom andamento do trabalho nas unidades.

Quando tem dificuldades que envolvem meu trabalho e o trabalho deles, normalmente a gente conversa e muda. Quando uma coisa não está saindo bem, a gente se reúne e conversa. (ENF 1)

Entretanto, esta segurança, segundo os enfermeiros, também pode gerar impunidade, o que afeta o gerenciamento do pessoal com estabilidade no emprego. Isto acontece porque, ao mesmo tempo em que a condição de "igualdade" promove o trabalho, também traz conseqüências, como o questionamento de algumas atividades estipuladas ou a sua realização da maneira mais conveniente para o trabalhador e não para as necessidades do serviço.

A condição de igualdade também pode favorecer a quebra das hierarquias necessárias à organização do trabalho da Enfermagem. Sabe-se que é importante o tratamento igualitário aos trabalhadores, com respeito às diferenças individuais e às atividades diferenciadas que cada um realiza. Porém, há necessidade de limites que circunscrevam os direitos e deveres de cada categoria funcional na Enfermagem, sob pena de esfacelamento das relações profissionais, com conseqüente repercussão no trabalho assistencial ${ }^{(18)}$.

Os enfermeiros reconhecem que a segurança autorizada pela estabilidade é uma prerrogativa do serviço público, uma vez que em instituições privadas é evidente a insegurança enfrentada pelos trabalhadores em decorrência da falta de possibilidade de diálogo, medo, abuso de poder das chefias, intrigas, demissão sumária e da perda do emprego ${ }^{(19)}$. No setor público, entretanto, existe o estereótipo de que os trabalhadores não 
podem ser punidos devido à condição de estabilidade, diferentemente do setor privado, no qual os gerentes contam com a "arma da punição", ou seja, a possibilidade de demissão do funcionário ${ }^{(20)}$. No relato a seguir, a enfermeira discorre sobre a dificuldade encontrada no setor público para repreender ou punir os trabalhadores que não correspondem às necessidades do trabalho da enfermagem.

Se pensar em dificuldades e facilidades, a outra era mais fácil [serviço privado]. A questão do mais fácil é tu conseguires mudanças com mais rapidez, mudanças no comportamento, mudança de um funcionário, substituição de funcionário. (ENF 16)

No hospital público, para demitir um funcionário, os enfermeiros precisam instaurar um processo administrativo contra o trabalhador e, na maioria das vezes, devido ao desgaste nesse percurso, muitos se omitem, pois reconhecem que toda essa "perda de tempo" acabará resultando, no máximo, em advertência verbal.

Vou passar por todo um desgaste, todo um processo, um confronto com o funcionário que vai continuar trabalhando comigo e que, no final, talvez o xxx resolva dar uma advertência. Isso, quando ele não engaveta o processo e, provavelmente, essa advertência vai ser verbal. O xxx vai chamar o funcionário lá fora, vai dar uma conversadinha e deu. E tu vais continuar com aquele funcionário. Então, realmente, o sistema não ajuda. (ENF 3)

Aqui, tu levas uma advertência e não acontece nada. No máximo, te chamam a atenção, te levam numa salinha e falam, e deu. Então, na verdade, não acontece muita coisa. (ENF 9)

Para a maioria dos entrevistados, gerenciar os trabalhadores da Enfermagem em serviços públicos de saúde deixa-os de "mãos amarradas", devido à impunidade conferida pelo emprego estável. Ao surgirem problemas de impontualidade ou faltas, por exemplo, o enfermeiro acaba por não advertir o funcionário sobre essas condutas, pelo fato de que isto possivelmente não resultará em sanções, ele ficará desautorizado perante a equipe e ainda continuará a conviver com o funcionário, trabalhando na mesma unidade.

Assim, as situações de atraso são reconhecidas pelos entrevistados como algo intrínseco à personalidade dos trabalhadores. Identificam-nas como condições "crônicas", que não têm "cura". Para não gerar desentendimentos, os enfermeiros acabam agindo como se isso fosse normal, parte da rotina de trabalho.

Tem uma funcionária que chega atrasada, mas é hábito dela e não tem correção. Mas a gente até leva numa boa, porque já não tem mais conserto, não tem mais como meIhorar. (ENF 2).

É uma característica da pessoa. Têm pessoas da tarde, de anos, que tem problema crônico de atraso, mas isso é da pessoa mesmo. (ENF 7)
Os que não são assíduos, a equipe às vezes reclama, mas já se acostumou. Infelizmente, é uma coisa assim que não deveria acontecer, mas pra não ter briga, nem discussão, acaba-se aceitando essa situação. (ENF 14)

A banalização dos atrasos e do absenteísmo talvez seja uma maneira dos enfermeiros defenderem-se, em virtude de não terem controle sobre essas circunstâncias, nem medidas administrativas ágeis para resolver o problema. Entretanto, agindo desta forma, punem os trabalhadores pontuais, abrindo a possibilidade de que adotem esse mesmo comportamento.

A idéia de impunidade fica bem clara quando se observa que funcionários que trabalham no hospital universitário onde foi desenvolvida a pesquisa e em um hospital filantrópico localizado a alguns metros do primeiro saem mais cedo ou chegam mais tarde ao hospital universitário quando seus horários de entrada e saída são coincidentes. Isto ocorre porque, segundo os trabalhadores, no hospital filantrópico, a rigidez em relação à pontualidade é maior e eles podem ser advertidos e até demitidos pela recorrência de atrasos.

Diante do exposto, verifica-se que a segurança no trabalho proporcionada pela estabilidade no emprego, mesmo sendo uma condição que por vezes facilita o gerenciamento do enfermeiro, pode também prejudicar, e muito, esse gerenciamento, provocando situações que produzem desequilíbrios na condução do processo de trabalho coletivo.

\section{O (des)comprometimento no trabalho da enfermagem e a estabilidade no emprego}

Comprometimento significa "empenhar-se, adquirir responsabilidades"(21). O termo também pode referir-se a "engajamento, agregamento e envolvimento no trabalho"(22). Quando o trabalhador possui essas qualidades, ele desenvolve confiança e poder, o que resulta na realização das metas estabelecidas pela instituição em que exerce seu trabalho(23). Da mesma forma, o comprometimento ocorre sob a forma de manifestações observáveis que vão além das expectativas organizacionais normatizadas, como assiduidade, pontualidade, tempo de serviço e qualidade adicional no desempenho das tarefas ${ }^{(24)}$.

Toda empresa, quer seja pública ou privada, deseja que seus funcionários tenham esse sentimento de compromisso que os impulsiona a cumprir suas tarefas com responsabilidade e empenho. As organizações buscam por pessoas que não trabalhem apenas pelos benefícios imediatos, mas que se comprometam com o trabalho e a profissão(25). Em outras palavras, as organizações anseiam que os empregados "vistam a camisa", vibrem com as conquistas dos objetivos e trabalhem para que haja a otimização dos processos organizacionais.

No exercício de suas funções, os trabalhadores dos hospitais públicos, em especial, deveriam comprometer-se com uma grande causa - a assistência de qualidade - que necessitaria ser abraçada e defendida como um ideal pessoal e profissional ${ }^{(11)}$.

Essa situação não foi encontrada na realidade pesquisada, uma vez que os entrevistados referiram que o comprometimento é visto como um diferencial, porém não obrigatório para o desempenho dos trabalhadores de Enfermagem. 
Para alguns enfermeiros, a estabilidade no emprego promove falta de compromisso com as atividades que devem ser realizadas, pois os funcionários fazem o mínimo, mesmo tendo a capacidade para fazer o máximo. Com isso, também existe a possibilidade de haver perdas na qualidade da assistência por ineficiência e falta de atenção às atividades da Enfermagem $^{(6,10,26)}$.

Ao se referir aos cuidados prestados aos pacientes pelos trabalhadores estáveis, um dos entrevistados (Enf 3) manifestou que muitos deles realizam apenas o estritamente necessário, enquanto outro (Enf 11) relatou que os cuidados aos pacientes são os básicos, isto é, nada além daquilo imprescindível para a efetivação da assistência mínima. Ademais, ocorreu a revelação de um grave problema:

Alguns, por se acharem estáveis dentro do local de trabaIho, são grosseiros com os pacientes. Alguns são relapsos. (ENF 14)

Tem algumas que não gostam, quando ficam nos xxxx, tratam os pacientes com um pouco de aspereza. [...] Quando elas ficam com os pacientes xxxx, elas mudam com o paciente: não gostam muito, porque acham que são muito solicitantes, que reclamam muito. (ENF 9)

Após serem selecionados em um concurso público e adquirirem estabilidade, muitos trabalhadores acomodam-se e não são poucos os casos de ineficiência e mau atendimento à população advindos do poder proporcionado pela estabilidade ${ }^{(27)}$. Entretanto, o cuidado, que é a essência do trabalho na Enfermagem, opõe-se ao descuido e ao descaso, pois cuidar é uma atitude, é mais do que um simples momento de atenção, é ter responsabilidade, envolvimento e preocupação pela vida do outro. O cuidado é a essência humana ${ }^{(28)}$ e ações simples de solidariedade provocam diferença no atendimento oferecido pela equipe de Enfermagem.

Os profissionais de Enfermagem estão presentes em todas as instituições assistenciais de saúde. Na rede hospitalar, permanecem 24 horas por dia, nos 365 dias do ano, o que revela a essencialidade das ações que desenvolvem ${ }^{(29)}$. Pela legislação que rege a profissão, é dever de todos profissionais de Enfermagem, sejam eles técnicos de Enfermagem, auxiliares, parteiras ou enfermeiros, prestar a assistência de qualidade, havendo diferenças apenas quanto aos procedimentos que cabem a cada um, conforme sua formação ${ }^{(12)}$.

Além disso, o código de ética dos profissionais de Enfermagem $^{(30)}$, em vigor desde 2000, preconiza que o pessoal de Enfermagem preste assistência acessível a toda população, sem riscos ou danos, respeitando a vida, a dignidade e os direitos humanos, em todas as suas dimensões.

No presente estudo, essa visão é reiterada pelos enfermeiros que entendem que o compromisso profissional deve ir além do regime de trabalho a que o trabalhador é submetido, como pode ser depreendido da fala a seguir.

Eu acho que isso não pode ser encarado como:- "Ah! Eu sou concursado e, agora, deu!" Eu acho que o compromisso profissional independe disso, né? Porém, em alguns situações, a gente vê esse comportamento. (ENF 16)

Ao ingressar no serviço público, os profissionais da saúde deveriam ter a compreensão de que sua missão é maior que sua condição de estável. Entretanto, um estudo realizado com trabalhadores com estabilidade no emprego constatou que $38 \%$ das diferentes categorias de servidores de um hospital público relataram que a principal razão para sua entrada em um serviço público foi a perspectiva de um emprego estável. $\mathrm{Na}$ mesma pesquisa, apenas $5 \%$ dos entrevistados referiu a estabilidade no emprego como a principal razão para o desenvolvimento de um bom trabalho ${ }^{(10)}$.

Isto é preocupante porque, embora proporcione segurança no trabalho, melhores salários e mais direitos, a estabilidade no emprego não garante o aumento da qualidade da assistência, que deveria ser o foco principal no trabalho da equipe de Enfermagem. A assistência/cuidado e a satisfação produzida pela sua efetividade necessitariam ser as marcas distintivas dos trabalhadores da saúde, independentemente de seu regime de trabalho ${ }^{(11)}$.

Os excertos a seguir deixam evidente que, na prática, a estabilidade no emprego não significa desenvolver um bom trabalho:

O pessoal vai pro descanso, mas ainda não fez a medicação de seus pacientes. Daí, durante o descanso, piora. Daí os colegas têm que fazer tudo. Daí ele volta e ainda fica reclamando. (ENF 9).

Há falha no cuidado. O cuidado podia ser melhor, mas não é. (ENF 1)

Esses depoimentos ilustram algumas das dificuldades para o gerenciamento do trabalho da equipe de Enfermagem que são atribuídas pelos enfermeiros à estabilidade no emprego. Quando há falta de compromisso com o trabalho, há diminuição da qualidade da assistência prestada pelo profissional de Enfermagem, pela negligência de deveres e obrigações, perdendo-se a essência da profissão que é o cuidado ao paciente. Percebe-se que, quando isso acontece, a condição de ser servidor público estatutário está acima da condição de ser profissional da Enfermagem.

\section{CONSIDERAÇÕES FINAIS}

Este estudo apresentou resultados e discussões advindos do objetivo proposto, qual seja, identificar a percepção dos enfermeiros sobre o gerenciamento do pessoal de Enfermagem de um hospital público cujos trabalhadores de Enfermagem contam com estabilidade no emprego. A temática escolhida foi desafiadora e propiciou uma imersão no mundo do gerenciamento do pessoal de Enfermagem na especificidade desse tema.

O método empregado - Análise Temática - forneceu subsídios importantes e mostrou-se adequado à investigação. As limitações da pesquisa ocorreram por conta da dificuldade em entrevistar as enfermeiras, que referiam não ter tempo para 
responder às perguntas, sendo que duas negaram-se a participar. Isto talvez esteja relacionado ao fato de que muitas investigações estão sendo realizadas simultaneamente no Hospital Universitário, e também pela alegação de que os resultados das pesquisas não conduzem à resolução dos problemas que são encontrados.

As categorias empíricas $A$ segurança no trabalho versus a impunidade proporcionada pela estabilidade no emprego e O (des)comprometimento no trabalho da Enfermagem e a estabilidade no emprego conduziram a algumas constatações que podem ser motivo de reflexão tanto para os enfermeiros envolvidos na pesquisa quanto para todos aqueles empenhados em manter a Enfermagem no mais alto grau de excelência profissional. Em síntese:

- a segurança no trabalho promovida pela condição de igualdade entre trabalhadores e enfermeiras pode favorecer a quebra das hierarquias necessárias à organização do trabalho da enfermagem;

- há necessidade de limites que circunscrevam os direitos e deveres de cada categoria funcional da Enfermagem, sob pena do esfacelamento das relações profissionais, com conseqüente repercussão no trabalho assistencial;

- a impunidade nos serviços públicos gera banalização das transgressões, que talvez seja a maneira das enfermeiras defenderem-se, em virtude de não terem controle desta situação e não disporem de medidas administrativas ágeis para resolver o problema;

- o gerenciamento do pessoal de Enfermagem em serviços públicos de saúde é muito diferente daquele exercido nos serviços privados, evidenciando a falta de instrumentalização do enfermeiro para a realidade dos hospitais públicos;

- a estabilidade proporciona segurança no trabalho, melhores salários e mais direitos, mas não garante o aumento da qualidade da assistência, que deveria ser o foco principal no trabalho da Enfermagem;

- o compromisso profissional da Enfermagem deve ir além do regime de trabalho;

- as desvantagens da estabilidade no emprego conseguem sobrepor-se às vantagens.

Diante do exposto, recomenda-se um acompanhamento dos trabalhadores dos hospitais públicos que possibilite detectar as adversidades encontradas e apontadas pelos enfermeiros e analisadas nesta pesquisa, abordando-as em programas de educação continuada.

Existe urgência de maior instrumentalização dos enfermeiros, tanto na academia quanto na realidade hospitalar, para novas formas de gerenciamento do pessoal de Enfermagem que goza de estabilidade no emprego que contemplem simultaneamente as necessidades organizacionais e o compromisso com a assistência de qualidade.

A título de reflexão final, cabe ressaltar que somente a aprovação e a classificação em concurso público não permitem avaliar o comprometimento dos trabalhadores antes de serem contratados. Como alternativa para amenizar as dificuldades identificadas por este estudo, resta mobilizar a equipe de Enfermagem e enfatizar o compromisso ético de cada profissional, que vai muito além de um emprego que forneça estabilidade.

\section{REFERÊECIAS}

1. Brasil. Lei n. 8.112, art. 20 de 11 de dezembro de 1990. Dispõe sobre o regime jurídico dos servidores públicos civis da União, das autarquias e das fundações públicas federais. [citado em 8 Nov 2009]. Disponível em: http:// www3.dataprev.gov.br/sislex/paginas/42/1990/8112.htm

2. Brasil. Emenda Constitucional n. 19, art. 41 de 1998. Modifica o regime e dispõe sobre princípios e normas da Administração Pública, servidores e agentes políticos, controle de despesas e finanças públicas e custeio de atividades a cargo do Distrito Federal, e dá outras providências. [citado em 21 Nov 2009]. Disponível em: http://www.observarh. org.br/nesp/projetos/rhsus/pdfs/ec19 98.PDF

3. Codo VP. Por uma psicologia do trabalho. São Paulo: Casa do Psicólogo; 2006.

4. Pessoa MMM. O emprego público no Brasil, nos anos 90. Ensaios FEE 2003;24(1):249-70.

5. Pizolli LML. Qualidade de vida no trabalho: um estudo de caso com as enfermeiras do hospital Heliópolis. Ciênc. Saúde Colet. 2005;10(4):1055-62.

6. Pires JCS, Macêdo KB. Cultura organizacional em organizações públicas no Brasil. Rev. Adm. Pública 2006;40(1):81-105.
7. Batista AAV, Vieira MJ, Cardoso NCDS, Carvalho GRP. Fatores de motivação e insatisfação no trabalho do enfermeiro. Rev. Esc. Enferm. USP 2005;39(1):85-91.

8. Ministério da Saúde. Cadastro nacional dos estabelecimentos de saúde do Brasil - CNES. [citado em 6 Nov 2009]. Brasília; 2009. Disponível em: http://tabnet.datasus.gov.br/cgi/tabcgi.exe?cnes/cnv/prid02br.def

9. Mellara SVG, Beccaria LM, Carta A, Contrin LM. Motivação da equipe de enfermagem em uma unidade de Terapia Intensiva. Arq. Ciênc. Saúde 2006;13(3):61-9.

10. Vaistman, J. Gerencialismo, cultura e expectativas entre servidores públicos de saúde. Rev. Adm. Pública 2001;35(1):29-47.

11. Vaghetti $\mathrm{HH}$. As perspectivas de um retrato da cultura organizacional de hospitais públicos brasileiros: uma tradução, uma bricolagem [tese]. Florianópolis (SC): Programa de Pós-Graduação em Enfermagem, Universidade Federal de Santa Catarina; 2008.

12. Conselho Federal de Enfermagem. Lei n. 7.498/86 artigo 11. Dispõe sobre a regulamentação do exercício da enfermagem e dá outras providências. [citado em 8 Nov 2009]. Disponível em: http://site.portalcofen.gov.br/node/4161. 
13. Bardin L. Análise de conteúdo. Lisboa: Edições 70; 2002.

14. Silveira RC. Estabilidade no emprego: possível, urgente, revolucionária [dissertação]. Porto Alegre (RS): Faculdade Livre de Direito de Porto Alegre, Universidade Federal do Rio Grande do Sul; 2005.

15. Magalhães ZR, Matos E, Gonçalves JR, Moreira LC, Gonçalves L, Espinoza LM et al. Algumas considerações acerca do processo de viver humano de técnicos(as) de enfermagem recém-admitidos(as) em um hospital escola. Texto Contexto Enferm. 2006;15(espec):39-47.

16. Mizobuchi LEC, Cury CFMR. Estresse na enfermagem: mensuração das situações geradoras em um hospital geral. Rev. Inst. Ciênc. Saúde 2007;25(4):349-55.

17. Brasil. Lei n. 9527 de 10 de dezembro de 1997. Altera dispositivos das Leis n.s 8.112, de 11 de dezembro de 1990, 8.460, de 17 de setembro de 1992, e 2.180, de 5 de fevereiro de 1954, e dá outras providências. [citado em 19 Ago 2010]. Disponível em: http://www.planalto.gov.br/ ccivil_03/Leis/L9527.htm

18. Vaghetti HH, Padilha MI, Silva RC, Simões JMTA. TrabaIho como subsistência nos hospitais públicos brasileiros. Rev Bras Enferm. 2009;62(6):906-911.

19. Betiol MIS, Tonelli MJ. Absenteísmo e comprometimento: algumas reflexões a partir de um estudo de caso analisado sob a ótica da psicodinâmica do trabalho. Ação Ergonômica 2003; 1(4):34-45.

20. Malik AM. Qualidade em Serviços de Saúde nos Setores Público e Privado. Cad Fundap 1996;19:7-24.

21. Amora AAS, Alves AT. Minidicionário da língua portuguesa. São Paulo: Saraiva; 2009.

22. Bastos AVB. O Conceito de comprometimento: sua natureza e papel nas explicações do papel humano no trabalho. Salvador: Organização e Sociedade; 1994.
23. Pepe CR, Quadros LRD. Liderança: evidenciando a importância de um líder dentro da organização (estudo de caso). Revista Eletrônica Lato Sensu [periódico online] 2008 Mar [citado em 14 Jun 2010]; 3(1). Disponível em: http://web03.unicentro.br/especializacao/ Revista Pos/P\%C3\%A1ginas/3\%20Edi $\%$ C3 $\%$ A $7 \% C 3 \% A 30 /$ Aplicadas/PDF/19-Ed3_CS-Evidenciand.pdf

24. Bastos AVB, Brandão MGA, Pinho APM. Comprometimento organizacional: uma análise do conceito expresso por servidores universitários no cotidiano de trabalho. Rev. Adm. Contemp. 1997;1(2);97-120.

25. Medeiros CAF, Enders WT. Validação do modelo de conceitualização de três componentes do comprometimento organizacional (Meyer e Allen, 1991). Rev. Adm. Contemp. 1998;2(3):67-87.

26. Ávila GGF. Elementos da cultura de um hospital universitário: repercussões no comportamento organizacional [dissertação]. Rio Grande (RS): Programa de Pós-Graduação em Enfermagem, Universidade Federal do Rio Grande; 2006.

27. Jornal Gazeta. População se queixa de mau atendimento em serviços públicos na Grande Vitória. [online]. Rio de Janeiro; 2009. [citado em 26 Set 2009]. Disponível em: http:// gazetaonline.globo.com/_conteudo/2009/09/539977-popu lacao + se + queixa + de + mau + atendimento + em + servico $\mathrm{s}+$ publicos + na + grande + vitoria.html

28. Boff L. Saber cuidar: ética do humano, compaixão pela terra. Petrópolis: Vozes; 1999.

29. Pires D. A enfermagem enquanto disciplina profissão e trabalho. Rev. Bras. Enferm. 2009;62(5):739-44.

30. Conselho Federal de Enfermagem. Resolução n. 240/2000. Aprova o Código de Ética dos Profissionais de Enfermagem e dá outras providências. [citado em 22 Jun 2010]. Disponível em: http://www.portalcofen.gov.br/ sitenovo/node/4280. 